\title{
Research on the Verification of Game Development by Emotional Interaction Design
}

\author{
You Chen Ma ${ }^{1}$, SeongKi Kim², Seok-Kyoo Kim ${ }^{3 *}$ \\ ${ }^{1}$ Master, Student, Department of Game Design and Development, Sangmyung University, Seoul, Korea. \\ ${ }^{2}$ Assisistant Professor, Division of SW Convergence, Sangmyung University, Seoul, Korea. \\ ${ }^{3}$ Assisistant Professor, Department of Game Design and Development, Sangmyung University, Seoul, Korea.
}

ORCIDs: 0000-0002-2664-3632 (SeongKi Kim), 0000-0003-4725-0288 (Seok-Kyoo Kim)

${ }^{*}$ Corresponding Author

\begin{abstract}
In previous research, the study began with the most basic interaction design to explore the emotional elements in the design process. Finally, based on the emotional design theory proposed by Donald Arthur Norman, and referring to the Flow theory proposed by Csikszentmihalyi and the hierarchy of needs theory proposed by American psychologist Abraham Harold Maslow, the author analyzed how to judge the pros and cons of emotional interaction design in games. The result proves that the emotional design that enables the player to be satisfied and self-realization in the process of using the interactive interface, interactive method, interactive experience, etc, is the truly excellent emotional interactive design. But if it is specific to the game, can the researched emotional interaction design theory make players emotionally happy and satisfied? The game development is based on the emotional interaction as the core of this design, and the differentiated design is made in the aspects of interactive interface, interaction mode, and interactive experience. The purpose is to use the three aspects introduced in the theory of emotional design to influence the emotions and emotions of the players to provide a basis for verifying the relevant views.
\end{abstract}

Keywords: Emotional interaction design, Emotional design theory, Flow theory, Demand hierarchy theory

\section{INTRODUCTION}

Today, information technology is developing rapidly. The existing interactive design can no longer meet user requirements, and users have put forward more demanding requirements on user experience. The concept of user experience has expanded from usability and ease of use for design purposes to emotional and interesting moods. Emotional interaction design has gradually become the focus of attention of researchers and designers in the information age, and it has become a new trend in user experience design. In this case, meeting the emotional needs of the user is critical.

In previous research, the existing game cases were used as the basis to analyze the emotional interaction design for the game. And by collating the analysis results, based on the three levels of emotional design proposed by Donald Arthur Norman, while referring to the Flow theory proposed by Csikszentmihalyi and the hierarchy of needs theory proposed by Abraham Harold Maslow, how to judge the emotional interaction design in games.

The pros and cons have been verified [1] [2] [3]. The research reveals that emotional interaction has obvious advantages and disadvantages in game design through the emotional changes obtained by players during the game. However, to make the research on the theory of emotional interaction design truly applicable to specific games, and to enable players to get emotional pleasure and satisfaction in the process of the game, this design is based on the relevant theories derived from previous research. Based on the game development, we hope to provide a basis for verifying the relevant points.

\section{Theory}

\section{I Analysis of Game Control}

"Legends of the Three Kingdoms" [4] combines the characteristics of similar Western games, combined with the era of the Three Kingdoms of China, and uses identity, power, and camp as clues. Through a series of strategies and operations in the form of cards, the players finally win. The game is a collection of history, literature, art and other elements. And to a certain extent, although the settings are not the same, from a macro perspective, the games designed in this study have similarities in many aspects. For example, "Legends Of the Three Kingdoms" and the games designed in this study are all played against each other with a fixed number of cards. During the battle, the different skills the player has will also have different effects on the game's battle process.

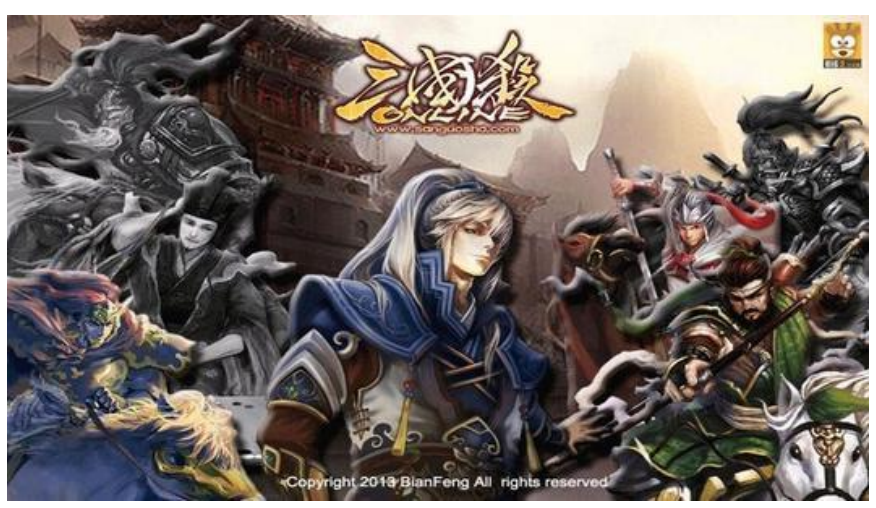

Fig. 1. Legends of the Three Kingdoms [4] 
On the other hand, just like the unique identity cards in "Legends of the Three Kingdoms", the games designed in this study have their own uniqueness. Differently from the fixed logic similar to "1 must be less than 2" in general games, all 54 battle cards used in the games designed in this study are referenced to the core of Chinese classical philosophy-the theory of Yin Yang Five Elements, that is, gold, wood, the changes of the five elements of water, fire, and soil, and the mutual transformation between yin and yang [5]. Based on this, the game creates unique rules of battle. With limited playing cards, you can create almost infinite combinations of changes. This test the player's ability to formulate the game tactics and the ability to react instantly than other card games of the same type.

\section{II Game Items}

\section{II. I Game summary}

At present, the dominant game types are MMORPG and PUBG-like sandbox games. But, this situation is gradually changing over time. More types of games have appeared online, and at the same time, player preferences have become more diverse. Therefore, if it is still blindly making MMORPG type or sandbox type games, it will become more and more difficult for players to get approval. On the contrary, if the development direction is focused on several other types of games, it may instead attract more players.

Among them, TCG games can still be said to be a virgin land. At present, there are many card games in China, and similarly, the number of card games in foreign game markets is not small. However, the number of domestic TCG card games is very small.

\section{II. II Analysis of related games}

\section{1) Advantages:}

(1) There are abundant changes between cards, and the system is novel, which can effectively attract new players to join.

(2) The demand for strategic tactics in the game will form an advantage to reduce the loss of high-end players.

(3) Because the game war is completely based on the changes between Yin Yang and Five Elements, the development of the basic part of the game will be relatively simple.

\section{2) Disadvantages:}

(1) The high entry threshold for games may lead to the loss of some players.

(2) Metaphysical elements such as yin, yang and five elements are complicated to change, and skill cards are added during the game battle, so there are certain difficulties in formulating relevant rules and in-depth development.

\section{III Game Concept and Design}

\section{III. I Basic elements of the game}

(1) Occupation: (1) Defiant Mortal(2) Xiuzhen(3) Qingwu Division(4) The Wizard of Qimen

(2) Battle cards: Yin Yang and Five Elements cards, a total of 54 cards.

(3) Skill Cards: Before the match starts, we can select three skill cards to configure as skill cards. The configured skill deck can be used in the battle. (Skill cards are different for different occupations)

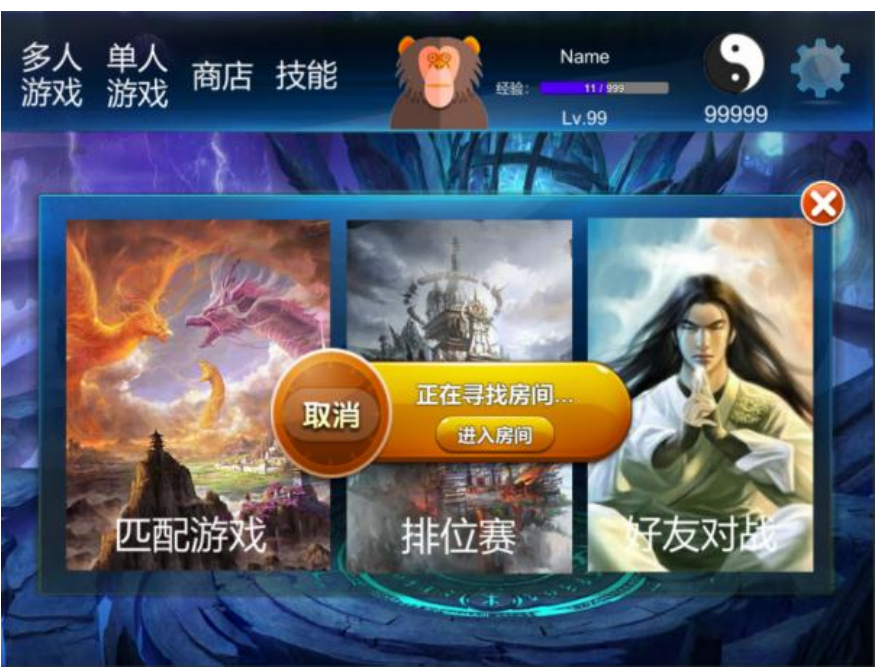

Fig. 2. Waiting interface for the game battle

(4) Battle: The rules are mainly based on the changes in the mutual relationship between Yin Yang and the Five Elements.

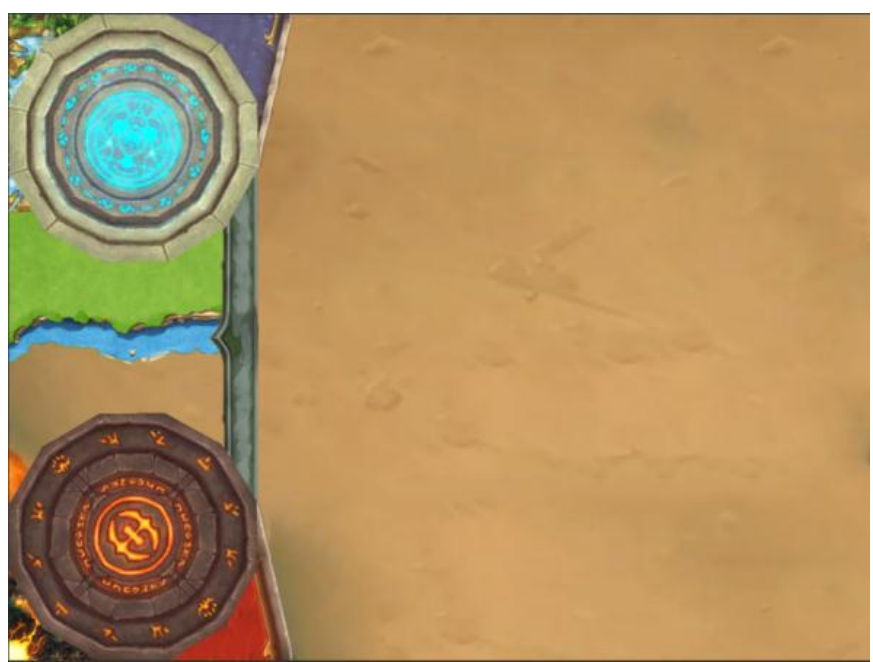

Fig. 3. Game battle interface 


\section{III. II Game Battle Cards}

Five Elements Card: Gold $1 \sim$ Gold 9 / Wood $1 \sim$ Wood 9 / Water $1 \sim$ Water 9 / Fire $1 \sim$ Fire 9 / Earth $1 \sim$ Earth 9 . A total of 50 photos.

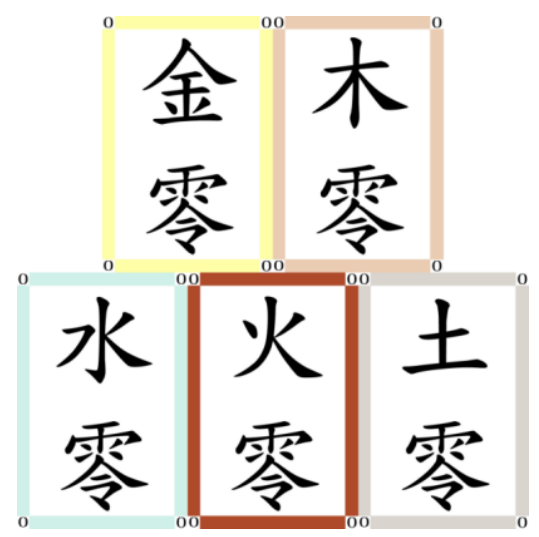

Fig. 4. Five Elements Card Style

Yin and Yang cards: Yin * 2 / Yang * 2, a total of 4 cards.
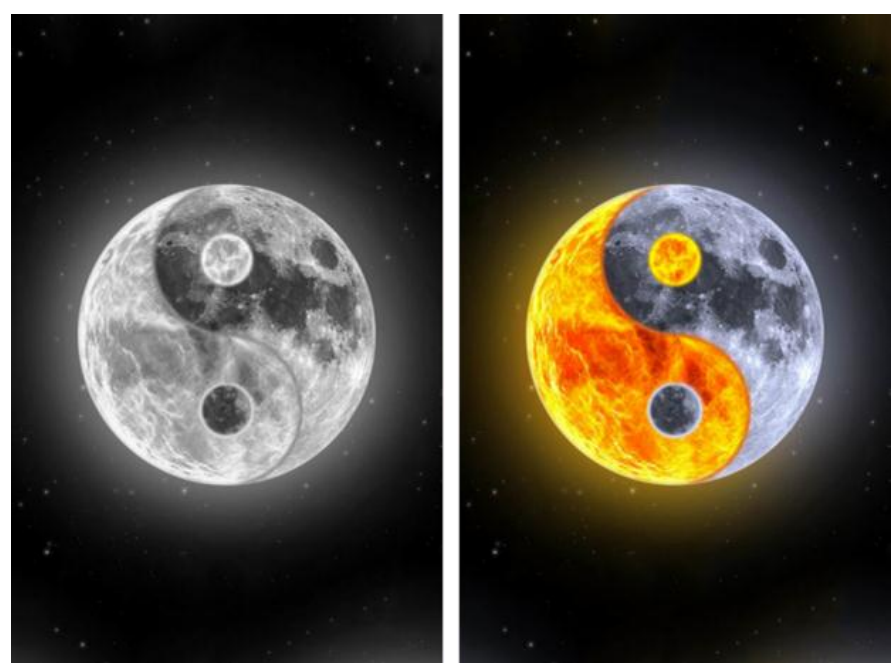

Fig. 5. Yin and Yang card style

\section{III. III Introduction to Game Profession}

\section{1) Defiant Mortal}

This profession is characterized by the setting of health. Under normal circumstances, 54 battle cards will be evenly distributed to the two opponents at the beginning of the battle, that is, two opponents hold 27 battle cards. When the profession holds cards, each battle card will give the profession a little health. That's 27 health.

During the battle, every time this card consumes a card, it will lose a little health. On the contrary, it will increase a little health. This class can use skills only when its health is consumed to half or less (14 health and below).

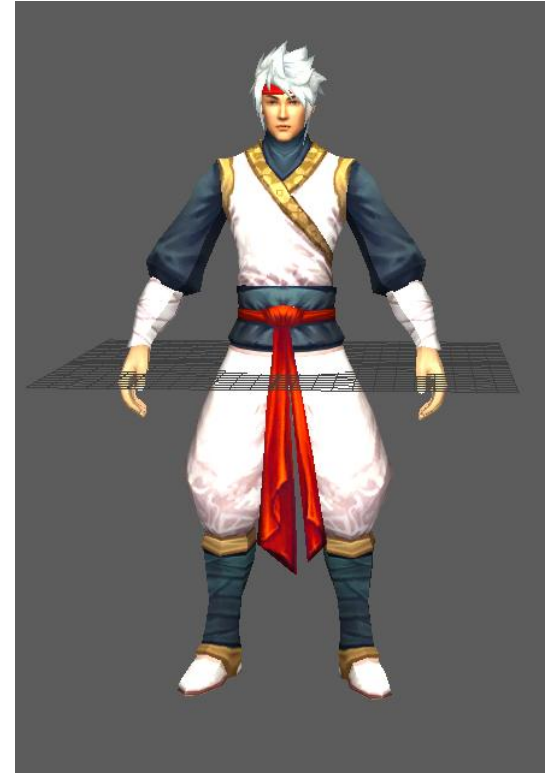

Fig. 6. Characters of Defiant Mortal profession in the game

This occupational setting is taken from the Mingpan (fate) of religion [6]. Mingpan began in the Tang Dynasty, with Nianzhu as the main body at the beginning, life-year stem as the main life, supplemented by Nayin method. Li Xuzhong of the Tang Dynasty changed the year to the main body, taking the four pillars of the year, month, day, and hour to push his fate. In the Northern Song Dynasty, Xu Ziping changed the day to "I (the Lord of the Sun)", so as to check the changes in the five elements in the four pillars as the focus of destiny, and carry forward. At present, the fate is estimated with eight characters, and all are based on Ziping law. Therefore, this fortune tellingis method also called "Zi Ping Fa" or "Zi Ping Ba Zi Xue".

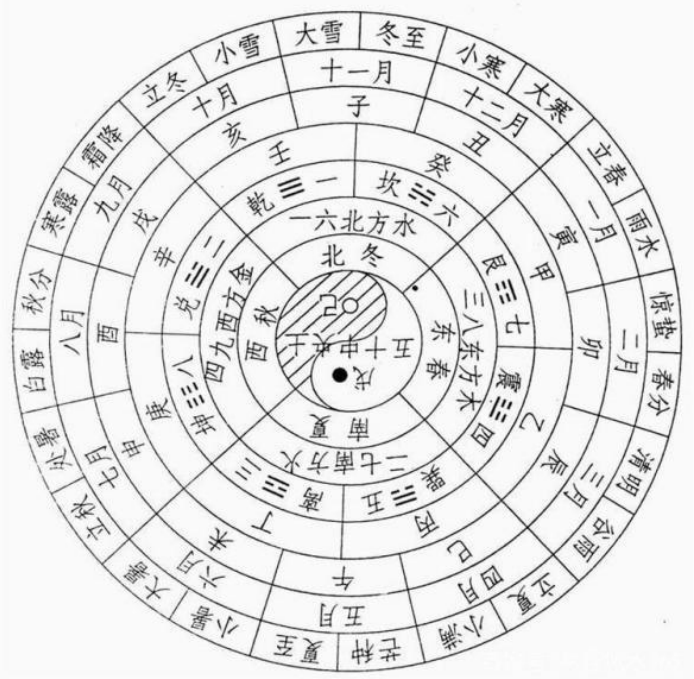

Fig. 7. Mingpan 
The skills of this profession are mainly derived from the related records of Mingpan in traditional yin-yang theory (E. g: "Skills-Gold in the Sea" turns all water attribute cards you hold into gold attribute cards).

The skills are from [7] as shown in Figure 8.

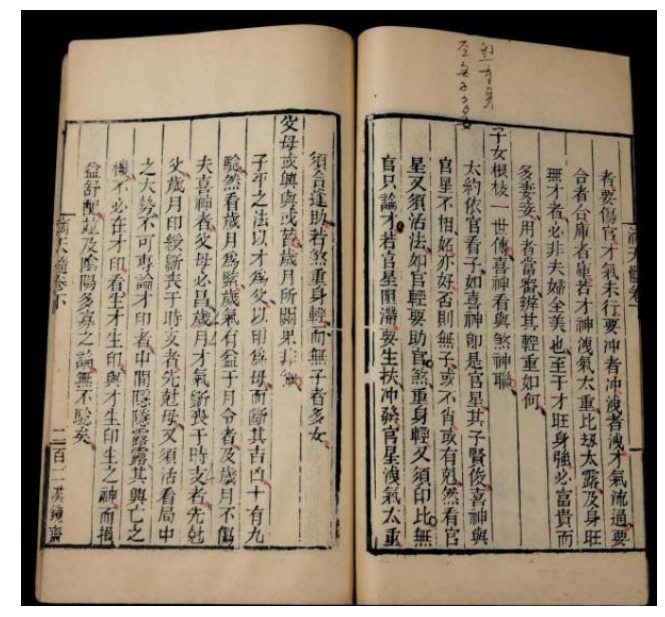

Fig. 8. Di Tian Sui

\section{2) Xiuzhen}

The profession is characterized by having the most skill types of all occupations, covering almost all areas of traditional metaphysics.

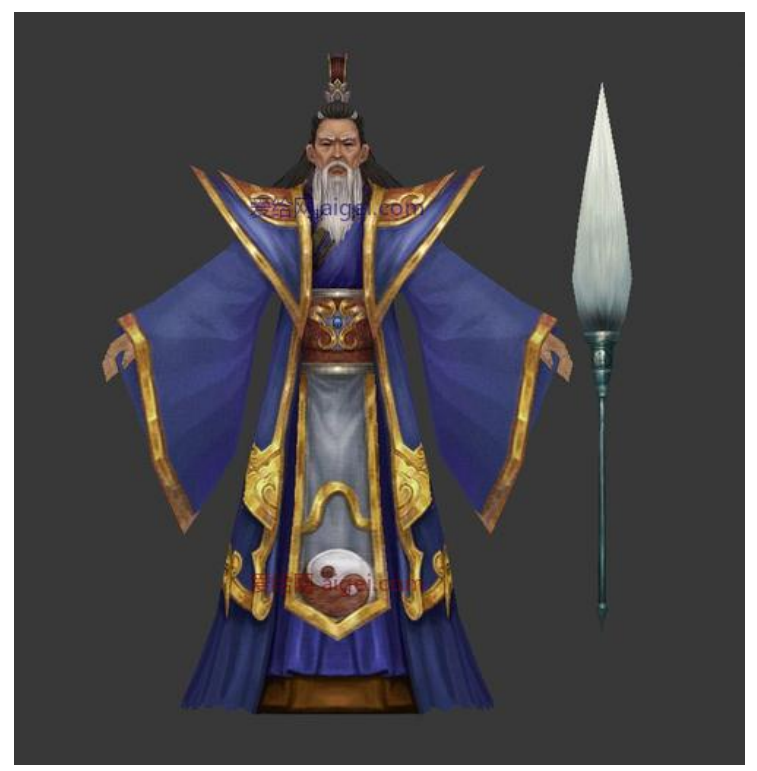

Fig. 9. Characters of the Xiuzhen profession in the game

Xiuzhen is also known as Xiuxian, Taoism, and cultivation. The occupational setting is taken from [8]. A Xiuzhen is a person who seeks to achieve real by practicing various Taoist methods.

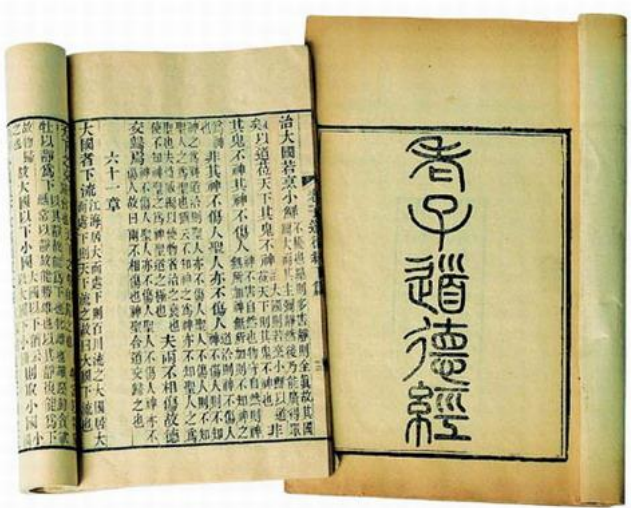

Fig. 10. Tao Te Ching

Mainly the ancient method of refining gas, guiding limbs, think carefully, inside and outside. Since ancient times in China, there have been numerous Taoist schools of cultivation. Taoism includes the branches of Zhengyi and Quanzhen, as well as many folk factions. Depending on the idea, the principles and laws held by them are different, each person's situation is different, and the exercises are also ever-changing (E. g: SkillsFive Thunders consumes one gold, wood, water, fire, and earth five cards each to generate one Five Thunder Cards. Five Thunders card effect is judged as restraining all five elements attribute cards, but will be restrained by Yin and Yang attribute cards).

The skills are from Wuleifa, a spell spell in Taoism. It became popular in the Song Dynasty. The gods of the Thunder Ministry will either be called Marshals or Tianjun, subject to Taiyi's temperance [9].

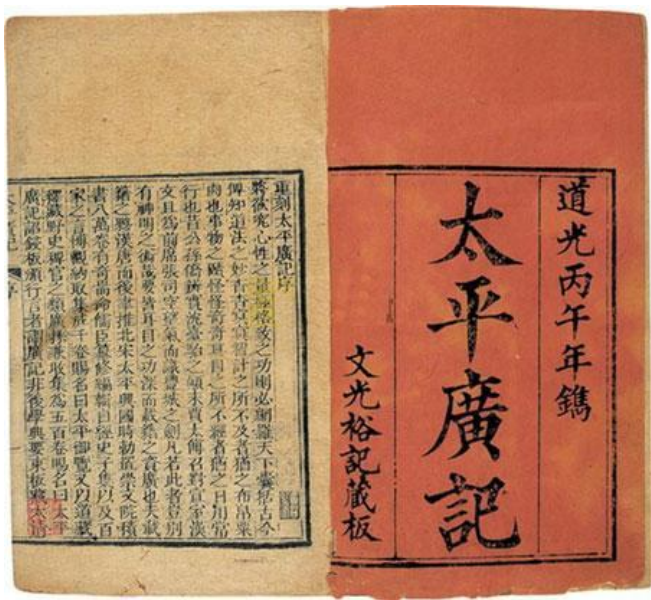

Fig. 11. Tai Ping Guang Ji 


\section{3) Qingwu Division}

The profession is characterized by a certain amount of feng shui values consumption to release skills. The accumulation of feng shui values depends on the number of cards used in battle. For each card used, the Feng Shui value of the class will increase a little. And this occupation is the only occupation that can continue to exert the effect of skills.

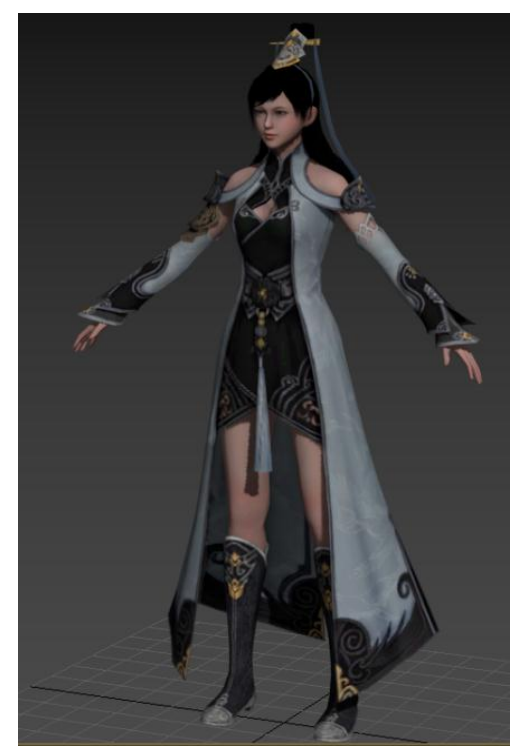

Fig. 12. Characters of the Qingwu Division profession in the game

This occupational setting is taken from the Qingwushu in the "Zang Jing", also known as Kanyushu. The book is written by Jinxian Shi and Guo Pu [10]. "Qingwu" was originally the name of the ancient Kanyu master in the legend. It was called "Qingwuzi" and was from the Shang and Zhou dynasties [11]. "Legend has it that Qingwuzi later founded Feng Shui, believing that the choice of the location of the ancestor's grave will affect the fate of future generations. Therefore, Qingwuzi is considered to be the first Mr. Fengshui in China. People in the Fengshui Kanyu line also regarded Qingwu as the ancestor, and thus Kanyushu was also called "Qingwushu".

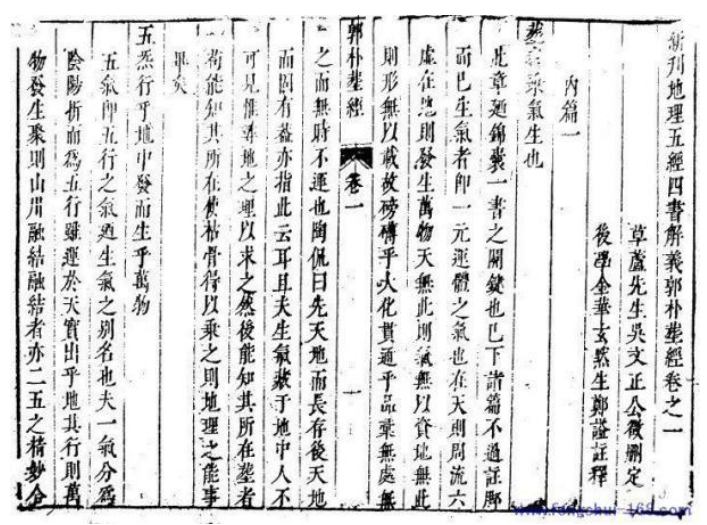

Fig. 13. Zang Jing
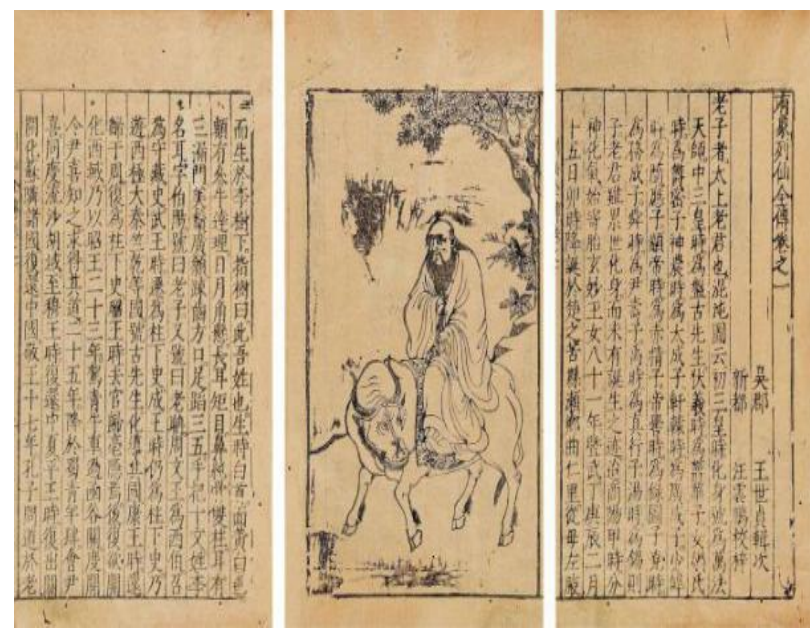

Fig. 14. Lie Xian Quan Zhuan

The world calls "Qingwushu" the first magical book in Fengshui. It mainly talks about Fengshui's ability to search for dragons. It has a huge influence in history, so that "Qingwushu" has become another name of Fengshui (For example, Skills-He Jin Shui causes the effect of the opponent's skill on him will be invalidated during the three rounds).

The skill, He Jin Shui, is the term of Feng Shui. The boundary of the seal around Xiaoming Hall of Zhixue Xin binds the veins of feng shui to form a barrier, which can shield doom and evil spirits. It is from [12].

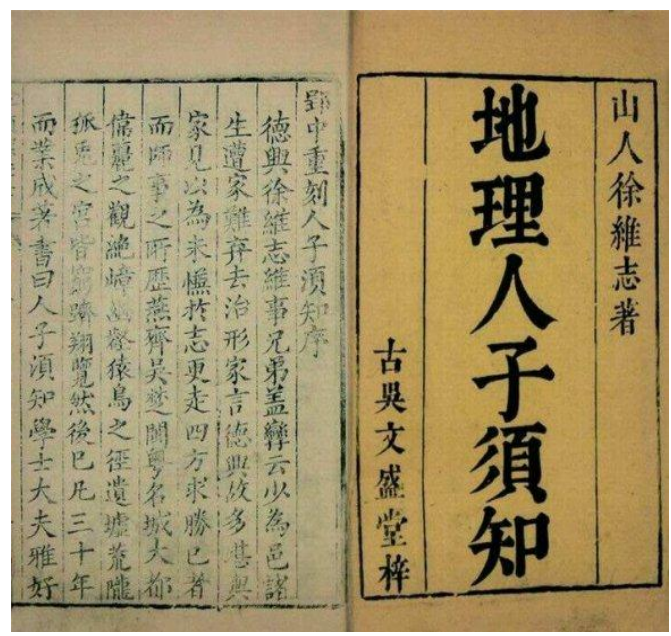

Fig. 15. Ren Zi Xu Zhi

\section{4) The Wizard of Qimen}

This occupation is the only occupation in all occupations that can use DunShu (can skip rounds during the battle)and Qimen spell (Exposing the opponent's card). 


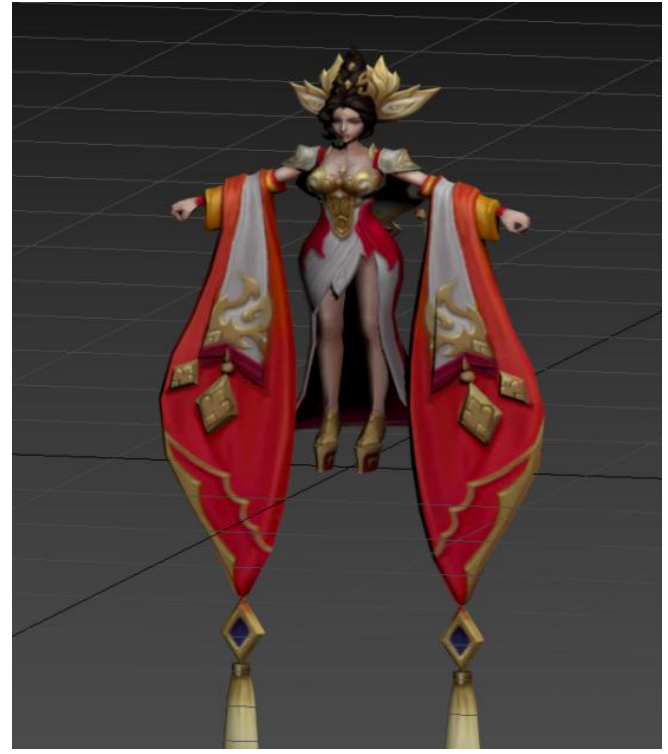

Fig. 16. Characters of the The Wizard of Qimen profession in the game

This occupation setting is taken from "Qimen Dunjia" [13]. "Qimen Dunjia" is an ancient Chinese book of numbers, and it is also the first of the three secrets of Qi Men, Liu Ren and Tai Yi. Its essence is an advanced astrophysics, revealing the interaction between the eight planets of the solar system and the Earth's magnetic field. When Qimen Dunjia was first founded, there were 4, 320 innings, and it was improved to 1, 080 innings after the wind. By the time of the Zhou Dynasty, Jiang Shang had been reduced to 72 innings because of the need for marching. After being taught by Huang Shigong in the Han Dynasty, Zhang Liang reformed again and became the 9th Yindun Bureau and the 9th Yangdun Bureau. "Qimen Dunjia" is the result of joint research by many generations in ancient China. It includes astronomy, calendar science, war science, strategy science, and philosophy.

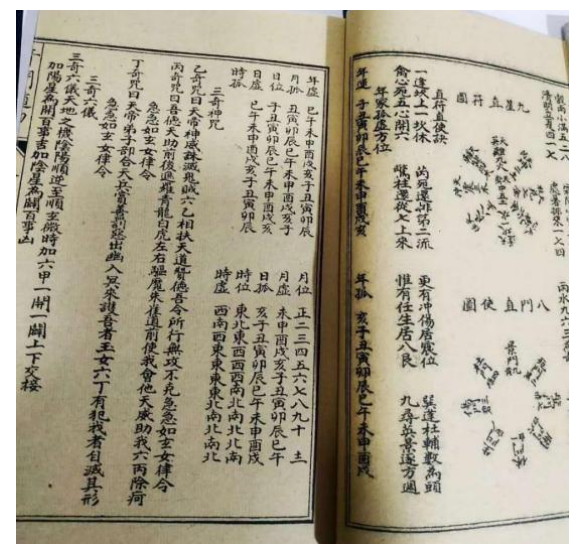

Fig. 17. Qimen Dunjia

Knowledge of astronomy, geography, mathematics, agronomy, folklore, economics, and military. In ancient times, it was used for state affairs and warfare. The Qimen Dunjia theory summarizes the factors that affect human survival and development into four aspects: time factor, space factor, human factor and unknowable mystery factor (For example, SkillsHibiscus Sunrise consumes a random wood attribute card to make all opponent's Yan attribute cards display and place).

\section{III. IV Rules of Battle}

Five Elements Card: $9>8>7>6>5>4>3>2>1>0$; If it is a symbiotic relationship, the value of the symbiotic attribute is +1 when determining the value of the card; If it is a grammatical relationship, the value of the grammatical attribute is -1 when determining the value of the card;

yin and yang: Restraint each other and all five cards.

Winning conditions: The 54 cards were distributed evenly to the opponents, and the player who ran out of all the opponent cards first won.

\section{CONCLUSION}

According to previous researches, excellent emotional interaction design in games is generally reflected in the instinctual hierarchical design of the interactive interface, the behavioral hierarchical design of the interactive mode, and the reflective hierarchical design of the interactive experience. The instinctual level design of the interactive interface is mainly aimed at the external look and feel of the game, which directly affects the player's feelings and emotions, and plays a dominant role with the physiological characteristics of the player's gaze, feeling and sound. The behavior level design of the interaction mode is mainly aimed at the player's experience. The main points of its design are focused on four elements: function, understandability, ease of use, and feeling, in order to allow players to get psychological pleasure. Finally, the reflective level design of the interactive experience involves many fields including identity, culture, and the spiritual connotation of the game, so it will stimulate different private memories for players, reflect on what they do, and build identity Identify and express emotional appeal. Therefore, the games designed and developed by this research started from the above three points and made different designs in aspects such as game interface, game mechanism, game rules, a game story, etc. The purpose is to use different channels to influence the player's emotions and emotions from the three major levels introduced above and establish a solid experimental basis for testing the conclusions of previous studies.

\section{REFERENCES}

[1] Abraham Harold Maslow. A Theory of Human Motivation Psychological Review. 1943.

[2] Csikszentmihalyi M. The Psychology of Optimal Experience. "New York: Harper and Row". 1990. 
[3] Donald Arthur Norman. Emotional Design: Why We Love (or Hate) Everyday Things ( Translation), "NewYork: BasicBooks". 2004.

[4] LEGENDS OF THE THREE KINGDOMS. BaiduLEGENDS OF THE THREE KINGDOMS. Baidu Encyclopediamarch [Internet]. 2020.

[5] Yin Yang Five Elements. Baidu-Yin Yang Five Elements. Baidu Encyclopediamarch [Internet]. 2020.

[6] Ming Ge. Baidu-MingGe. Baidu Encyclopediamarch [Internet]. 2020.

[7] Jingtu. Di Tian Sui. 1848.

[8] Lao Tzu. Tao Te Ching. Spring and Autumn Period.

[9] 14 persons including Li Fang, Hu Meng, Li Mu, Xu Xuan, Zhao Linji, Wang Kezhen, Song Bai, and Lu Wenzhong. Taiping Guangji. 978.

[10] Jinxian Shi, Guo Pu. Zang Jing. Eastern Jin Dynasty.

[11] Wang Shizhen Wang Yunpeng. Liexian Quan Zhuan. Ming Dynasty.

[12] Xu Shanji, RenZiXuZhi, Shui Fa. Ming Dynasty.

[13] Qimen Dunjia. Earliest from the period of myth. 